R. J. Cohen and W. T. Sullivan, III, eds.

\title{
The International Commission on Illumination - CIE: What It Is and How It Works
}

\author{
Christine Hermann \\ CIE General Secretary \\ CIE Central Bureau, Kegelgasse 27,A-1030 Vienna, Austria
}

\begin{abstract}
This paper explains the structure and organization of the International Commission on Illumination (CIE), shows how it works, and describes its objectives and achievements. It gives details on the technical work done in the CIE Divisions and Technical Committees, and mentions some examples of the work in progress, emphasising those in connection with the subject of this conference. Quality lighting is the key to reducing light pollution. CIE is aware of the problem and takes it very seriously. CIE Divisions are working on problems such as glare, quality lighting, light trespass, light pollution and energy efficiency. In this endeavour CIE is also co-sponsoring this conference.
\end{abstract}

\section{Background}

As its name implies, the International Commission on Illumination - abbreviated as CIE from its French title "Commission Internationale de l'Eclairage" - is an organization devoted to international cooperation and exchange of information among its member countries on all matters relating to the science and art of light and lighting. The CIE is an autonomous organization. It was not appointed by any other organization (political or otherwise) but has grown out of the interests of individuals working in illumination.

Its predecessor, the "International Commission on Photometry", was founded in 1900 as the first international body concerned with light measurement (of incandescent gas lamps at that time). As the new technology of illuminating engineering developed rapidly, the measurement of light sources became only part of a much wider activity: the study of how to best use the light which these sources provided. Thus a widening of the Commission's scope was suggested, and an enlarged Commission, the present CIE, was founded in 1913.

Since then, the CIE has gained a worldwide reputation for developing sound guides for lighting practice. These guides are not arrived at lightly, but take into account the vast knowledge of how light and lighting influence visibility, visual and human performance, ease of seeing, visual comfort, safety and security. In addition, they also include consideration of the available light sources, luminaires, lighting techniques and economics.

Since its inception, the CIE has been accepted as representing the best authority on the subject, and as such it is today recognized by the International Organization for Standardization ISO and the International Electrotechnical Commission IEC as an international standardization body. Its standards are 
submitted to ISO or IEC for direct endorsement and issued as a joint double-logo standard. In those areas where the domains overlap or complement each other, standards are jointly developed. Recently an agreement on technical cooperation between CIE and CEN was signed, with the aim to enhance collaboration and avoid duplication of work. Thus worldwide standardization on fundamentals and metrology of lighting and signalling and related applications of light and colour rely greatly on the CIE.

\section{Objectives of the CIE}

The CIE is a technical, scientific and cultural non-profit organization whose objectives are:

1. To provide an international forum for the discussion of all matters relating to the science, technology and art in the fields of light and lighting and for the interchange of information in these fields between countries.

2. To develop basic standards and procedures of metrology in the fields of light and lighting.

3. To provide guidance in the application of principles and procedures in the development of international and national standards in the fields of light and lighting.

4. To prepare and publish standards, reports and other publications concerned with all matters relating to science, technology and art in the fields of light and lighting.

5. To maintain liaison and technical interaction with other international organizations concerned with matters related to science, technology, standardization and art in the fields of light and lighting.

It is important to note that in these objectives light and lighting embraces such fundamental subjects as vision, photometry and colorimetry, involving natural and man-made radiations over the ultraviolet, visible and infrared regions of the spectrum. Furthermore, the applications cover all usage of light, indoors and out, including environmental and aesthetic effects, as well as means for the production and control of light and radiation. Recently the CIE created a new Division in the growing field of Image Technology. At the request of international and regional organizations, CIE is leading the efforts to standardize image technology.

\section{How CIE is Organized}

The affairs of the CIE are vested by the General Assembly, consisting of the Presidents of National Committees which have the responsibility for decisions on all matters relating to the organization (Figure 1). The composition of the National Committees varies from country to country, but each is required to represent and have the cooperation of all organizations having an interest in light and lighting. At the present time the CIE comprises 40 member countries: 


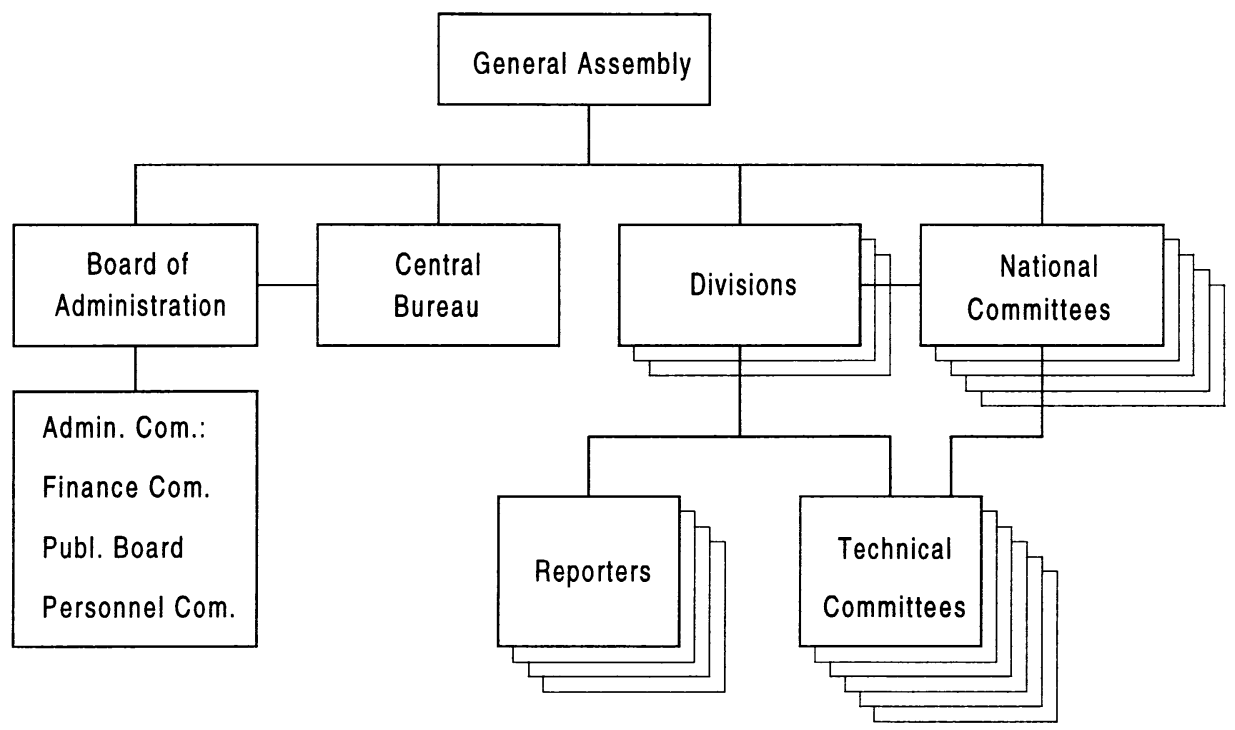

Figure 1. Organization of the CIE

$\begin{array}{llll}\text { Argentina } & \text { Denmark } & \text { Israel } & \text { Russian Federation } \\ \text { Australia } & \text { Estonia } & \text { Italy } & \text { Slovak Republic } \\ \text { Austria } & \text { Finland } & \text { Japan } & \text { Slovenia } \\ \text { Belgium } & \text { France } & \text { Moldova } & \text { South Africa } \\ \text { Brazil } & \text { Germany } & \text { Netherlands } & \text { Spain } \\ \text { Bulgaria } & \text { Great Britain } & \text { New Zealand } & \text { Sweden } \\ \text { Canada } & \text { Hong Kong } & \text { Norway } & \text { Switzerland } \\ \text { China } & \text { Hungary } & \text { Pakistan } & \text { Thailand } \\ \text { Croatia } & \text { Iceland } & \text { Poland } & \text { Turkey } \\ \text { Czech Republic } & \text { India } & \text { Romania } & \text { USA }\end{array}$

In addition, persons (or organisations) from countries where a National Committee has not yet been established may join as Associate Members and participate in the technical work of the CIE.

Modifications to the CIE Statutes were approved at our recent Session last month (June 1999), to add associate National Committee and supporting membership categories, with the goal of expanding CIE membership to encompass more regions in the world and to obtain financial support from other related organizations.

The affairs of the CIE are discussed and decided by the General Assembly (Figure 1), consisting of the Presidents of the National Committees. The General Assembly meets every two years. Decisions concerning admission and expulsion of members, approval of the budget and publication of Standards are taken by the National Committees. The National Committees delegate the conduct of affairs concerning technical issues to a Board of Administration. 
The success of an organization such as the CIE depends upon the effectiveness of its technical work. Indeed, the objectives of the CIE could not be attained without a suitable and active committee structure which draws upon the expertise of people from all the member countries. Each major subject of interest to the CIE was assigned to one of seven Divisions.

Each National Committee is entitled to have one voting member in each Division who keeps the information flow going and assures that information on the status of the technical work becomes known in the member countries.

Technical Committees (TCs), consisting of small international groups of experts, are established in each Division to work on a single subject. The intent is that such committees concentrate on one specific topic and render a report to the Division within a reasonable period of time, after which the committee is dissolved. TC Chairmen are nominated by the Division, and appoint the members of their TC. National Committees may also appoint a representative.

\section{How CIE Works}

The work programme can be divided broadly into two areas: fundamental research (covering such topics as vision, colour and measurement) and lighting applications. There is, of course, considerable interaction between these areas of activity.

\section{Division 1: Vision and Colour}

Terms of Reference: To study visual responses to light and to establish standards of response functions, models and procedures of specification relevant to photometry, colorimetry, colour rendering, visual performance and visual assessment of light and lighting.

Division 1 works on disability and discomfort glare, covering both fundamentals and specific applications such as discomfort glare experienced by elderly people. This work is much needed by the application divisions. In the colour field this Division is working on colour appearance models and colour rendering. One of the Technical Committees is working on the establishment of a colorimetric system based on fundamental visual functions. This work will eventually lead to a supplementary system of colorimetry.

Reports and standards have been published on: Colorimetry, CIE standard illuminants for colorimetry, CIE standard colorimetric observers, low vision, disability glare, industrial colour difference evaluation, CIE 1997 interim colour appearance model, etc.

The CIE work on colour, which led to the development of the colour rendering index, and on vision with the eye's response curve $V(\lambda)$, which allows meaningful values of lamp lumen output to be calculated for all light sources, provides the basis of every calculation carried out by lighting engineers throughout the world.

\section{Division 2: Measurement of Light and Radiation}

Terms of Reference: To study standard procedures for the evaluation of ultraviolet, visible and infrared radiation, global radiation, and optical properties of 
materials and luminaires, as well as the optical properties and performance of physical detectors and other devices required for their evaluation.

The Division's work ranges from fundamentals in the science of metrology to standards like the $V(\lambda)$ curve and a user guide for selection of illuminance and luminance meters. Reports have been published on: LED measurements, physical photometry, measurement of reflectance and transmittance, and other topics.

\section{Division 3: Interior Environment and Lighting Design}

Terms of Reference: To study and evaluate visual factors which influence the satisfaction of the occupants of a building with their environment, and their interaction with thermal and acoustical aspects, and to provide guidance on relevant design criteria for both natural and man-made lighting; as well as to study design techniques, including relevant calculations, for the interior lighting of buildings; incorporating these findings and those of other CIE Divisions into lighting guides for interiors in general, for particular types of interiors and for specific problems in interior lighting practice.

The Technical Committees can be divided into two groups dealing with either electric light or daylight. They work primarily on general aspects of light and light quality. Psychological aspects and post-occupancy evaluation and energy aspects are covered as well.

In the field of daylighting, a major undertaking of the CIE is in daylight data evaluation. Together with the WMO, CIE is conducting the International Daylight Measurement Program (IDMP). More than 50 IDMP stations are in operation around the world, collecting meteorological and light intensity data. The database is maintained on a webserver (http://idmp.entpe.fr).

Another area to mention is discomfort glare. A report on a Unified Glare Rating System (UGR) recommended by the CIE was published as CIE 117-1995.

Other TCs are dealing with questions such as museum lighting, lighting and architecture, and sky luminance models. Reports have been published on such topics as interior lighting, discomfort glare, daylight measurement, standard on overcast sky and clear sky. Last year the Division organised a very successful symposium on lighting quality.

\section{Division 4: Lighting and Signalling for Transport}

Terms of Reference: To study lighting and visual signalling and information requirements of transport and traffic, such as road and vehicle lighting, delineation, signing and signalling for all types of public roads and all kinds of users and vehicles, and visual aids for modes other than road transport.

TCs are working on road and tunnel lighting, colour of signal lights, crime and road lighting, etc. Reports have been published on road lighting, standards on road traffic lights, lighting in urban areas, daytime running lights, variable message signs, lighting of road tunnels and underpasses, and other topics.

TC 4-21 is working to produce an international framework to enable national or local regulations or recommendations to be produced to restrict interference by light with astronomical observations (see the paper by D. Schreuder in this volume). Three CIE publications deal specifically with light pollution around astronomical sites: 
- CIE 1-1980: Guidelines for minimizing urgan sky glow near astronomical observatories (jointly with IAU)

- CIE x008-1994: Urban sky glow, a worry for astronomy (Proceedings of a Symposium that brought together international experts on astronomy, lighting architecture, lighting engineering and instrumentation)

- CIE 126-1997: Guidelines for minimizing sky glow

This last Technical Report gives general guidance for lighting designers and policy makers on the reduction of sky glow, discussing briefly theoretical aspects of sky glow and giving recommendations about maximum permissible values for lighting installations in relation to the needs of astronomical observations.

\section{Division 5: Exterior Lighting and Other Applications}

Terms of Reference: To study procedures and prepare guides for the design of lighting for exterior working areas, security lighting, flood lighting, pedestrian and other urban areas without motorized traffic, areas for sports and recreation, and for mine lighting.

Division 5 also deals with light trespass. Based on a workshop on spill light, TC 5-12 (Obtrusive light) was established with the task to study the effects of obtrusive light from exterior lighting to residents and traffic, and to prepare a technical report that gives measures to describe the effects of light trespass, recommends measuring methods, and recommends acceptable levels. Reports have been published on all kinds of sports lighting, floodlighting, and lighting of exterior work areas.

\section{Division 6: Photobiology and Photochemistry}

Terms of Reference: To study and evaluate the effects of optical radiation on biological and photochemical systems (exclusive of vision).

TCs are working on standardization of sunscreen testing, photobiological lamp safety, effects of UVA radiation, standardization of action spectra, etc. Reports have been published on sunscreen testing, standardized erythema dose, and other topics. Last year the Division organised a workshop on Measurement of Optical Radiation Hazards.

\section{Division 7}

Division 7 "Generals Aspects of Lighting" was recently dissolved.

\section{Division 8: Image Technology}

Terms of Reference: To study procedures and prepare guides and standards for the optical, visual and metrological aspects of the communication, processing, and reproduction of images, using all types of analogue and digital imaging devices, storage media and imaging media.

TCs are working on gamut mapping, colour appearance models for colour management applications, communication of colour information, etc. The Division works in close liaison with other international standards bodies. 
Finally, as a project concerning all Divisions, CIE is working on the revision of the International Lighting Vocabulary (joint publication with the International Electrotechnical Commission (IEC), Publ. CIE 17.4-1987).

\section{Results of CIE Work}

\subsection{Publications}

The CIE produces a range of publications:

- Standards,

- Technical Reports and other technical publications,

- Proceedings of CIE Sessions and Symposia,

- disks (photometric and colorimetric tables, calculation software),

- a CD-ROM with all CIE Technical Reports, as well as individual CDROMs (on Low Vision, Proceedings of the last Session). More of these will be published in the near future.

More than 100 such publications have been issued.

Since 1991 when the agreement with ISO was ratified, three dual CIE/ISO standards have been published: one on Colorimetric illuminants (recently revised), one on Colorimetric observers, and one on Overcast sky and clear sky. Several drafts of standards are now in the pipeline.

The official languages of the CIE are English, French and German. Standards are published in all three languages, whereas other publications are written in English, with a summary in French and German.

In addition to Technical Publications, a newsbulletin, CIE News, is published quarterly. This gives regular updates on the progress of the technical programme, press releases of new CIE publications and forthcoming meetings, together with news of administrative matters and topics of general interest in the world of light and lighting. It is circulated free of charge to member bodies and is also included on our web home page.

The most up-to-date CIE information can be obtained via the Internet. The CIE home page is

\section{http://www.cie.co.at/cie/}

There you will find information on organizational structure, addresses of all our National Committees, a complete list of CIE publications together with abstract information, the contents of the most recent issues of $C I E N e w s$, information on upcoming symposia, as well as some other information of interest to those concerned with light and lighting.

Recently CIE has established a moderated E-mail Lighting List, for the exchange of research results and discussion on open questions. To join, just send an e-mail to

lsg-request@knt.vein.hu

with subscribe in the subject line. In addition, Division 3 has its own moderated discussion list:

lighting-request@garnet.nist.gov 


\subsection{Meetings and Symposia}

Every four years the CIE holds a Session, hosted by one of the member countries, which serves the purpose of bringing together all the representatives of the National Committees who are interested in the technical activities of the organization. The General Assembly meets to review and discuss the administrative and technical affairs of the CIE, make plans for the future, and elect the officers for the next quadrennium. The majority of the time, however, is taken up by an international lighting conference and meetings of the Divisions and Technical Committees where the programme for the past term is reviewed and the work for the next term is set up. The 24th Session was held in June 1999 in Warsaw, Poland. The next one is planned for San Diego, California, in 2003.

The first objective of the CIE, as stated in our Statutes, is "to provide an international forum for the discussion of all matters related to the science, technology and art of lighting". Seminars organised on various topical subjects are proving to be one effective way of achieving the objective.

Annual CIE expert seminars were started in 1990, and these have now become a regular event and have proved to be a great success:

- 1990: Light measurement

- 1992: Computer programs for light and lighting

- 1993: Advanced colorimetry

- 1994: Advanced photometry (Lighting quality and energy conservation)

- 1996: Colour standards for image technology

- 1997: Standard methods for specifying and measuring LED characteristics (Symposium and Tutorial Workshop)

- 1997: Colour standards for imaging technology

- 1998: Lighting quality

- 1998: Measurements of optical radiation hazards

- 1999: A symposium on 75 years of CIE photometry will be held in Budapest, Hungary, from 30 September to 2 October 1999.

\section{CIE Central Bureau}

The CIE headquarters are at:

Kegelgasse 27, A-1030 Vienna, Austria

Phone: +431 - 71431870

Fax: $+431-713083818$

E-Mail: ciecb@ping.at

We will be pleased to establish contact with our most qualified experts, for any lighting question you might have. 


\section{Conclusion}

Over the years the administrative and technical organization of the CIE has been modified to meet changing needs and conditions. However, its basic objectives remain the same. It is not unusual for CIE to respond to changing needs and conditions. New subject areas arise, while others lose importance. New technologies are developing, many of which involve aspects of light and lighting in disciplines not traditionally connected with CIE.

CIE is involved in a multidisciplinary field of endeavour. CIE combines the expertise of architects, designers, engineers, physicists, biologists, physiologists, psychologists, eye and health care professionals and many others in its technical work.

This Commission has grown through the engagement and enthusiasm of individuals. The number of member countries has grown from 9 to 40 since its foundation. Some two-thirds of the earth's land surface is now represented in the organization, by either National Committees or individual members.

In view of its authority and the global network it represents, the CIE is in an ideal position to play a key role in the continued progress towards a better-lit environment. 